\title{
Cinética de separación de Cu (II) por técnicas de flotación iónica, en celdas con dispersores flexibles ${ }^{(*)}$
}

\author{
M. Reyes*, F.J. Tavera**, R. Escudero**, F. Patiño*, E. Salinas* e I. Rivera*
}

\begin{abstract}
Resumen
Este estudio investiga y determina experimentalmente los parámetros cinéticos y el efecto de la modificación de las condiciones químicas e hidrodinámicas de las dispersiones aire-líquido, durante la separación de $\mathrm{Cu}$ (II) mediante técnicas de flotación iónica en celdas con dispersores porosos. Los resultados muestran que la eliminación de Cu (II) de la solución se puede llevar acabo por flotación iónica en una etapa, con 68 y 56 \% de recuperación y una concentración de xantato de $0,02 \mathrm{~g} / \mathrm{l}$, para los difusores de burbujas cilíndrico y plano, respectivamente. En sistemas multi etapas cinco celdas, se lograron recuperaciones superiores al 92 \% para ambas geometrías de dispersión. La constante cinética de flotación aparente mantiene un comportamiento lineal con los parámetros que caracterizan una dispersión ( $\mathrm{Jg}, \mathrm{e}_{\mathrm{g}}$ y $\mathrm{Db}$ ), hasta un punto donde la inestabilidad del proceso vuelve inoperable el sistema. Los resultados muestran que la remoción de iones de metal base por técnicas de flotación iónica se ve fuertemente afectado por los factores: concentración de colector [C], Jg, eg, Db, Jl y Sb.
\end{abstract}

Palabras clave Cinética; Flotación iónica; Cobre; Celdas; Gas retenido.

\section{Kinetics of $\mathrm{Cu}$ (II) separation by ion flotation techniques, in cells with flexible spargers}

\begin{abstract}
This research studies and experimentally determines the kinetic parameters and effect of modifying the hydrodynamics and chemical conditions of the air-liquid dispersions during the $\mathrm{Cu}$ (II) extraction by ion flotation techniques in cells with porous spargers. Results show that the elimination of $\mathrm{Cu}$ (II) from solution can be carried out by ion flotation in one stage, obtaining efficiencies of $68 \%$ and $56 \%$ for the flat and cylindrical sparger respectively with a xanthate concentration of $0,02 \mathrm{~g} / \mathrm{l}$. In multistage systems five cells, recoveries over $92 \%$ were achieved for both sparger geometries. The behavior of the flotation apparent kinetic constant is linear to the parameters that characterize dispersion $\left(\mathrm{Jg}, \mathrm{e}_{\mathrm{g}} \mathrm{y} \mathrm{Db}\right)$, until a point is achieved where the process instability makes the system inoperable. The results show that removing base metal ions by ion flotation is strongly affected by the following factors: collector concentration $[\mathrm{C}], \mathrm{Jg}, \mathrm{eg}, \mathrm{Db}, \mathrm{Jl}$ and $\mathrm{Sb}$.
\end{abstract}

Keywords

Kinetics; Ion flotation; Copper; Celds; Gas holdup.

\section{INTRODUCCIÓN}

La depuración de soluciones residuales, contaminadas con metales pesados, constituye un aspecto muy importante en la preservación del medio ambiente. La irresponsable descarga en drenajes, de estos residuos sin previo tratamiento, es el origen de contaminación de ríos, lagos y lagunas ${ }^{[1]}$.

Los métodos tradicionales de eliminación de metales pesados, tales como precipitación química, adsorción con carbón activado, intercambio iónico con resinas y electrolisis, son costosos e inapropiados para el tratamiento de grandes volúmenes de soluciones.

Una técnica prometedora y relativamente novedosa para tratar soluciones con metales pesados es la flotación iónica, presentada por F. Sebba ${ }^{[2]}$ en la década de los 60. La flotación, como proceso, tiene su origen en la concentración selectiva de minerales introducida por Haynes ${ }^{[3]}$, en 1860 , primeramente,

\footnotetext{
(•) Trabajo recibido el día 15 de enero de 2009 y aceptado en su forma final el día 26 de agosto de 2009.

* Universidad Autónoma del Estado de Hidalgo. Centro de Investigaciones en Materiales y Metalurgia, Carretera Pachuca Tulancingo Km. 4,5, C.P. 42184 Pachuca, Hidalgo, México.E-mail mar_77_mx@yahoo.com.mx

** Universidad Michoacana de San Nicolás de Hidalgo. Instituto de Investigaciones Metalúrgicas, C.P. 45000 Morelia, Michoacán, México
} 
empleando maquinas de flotación equipadas con un impulsor y un difusor instalados en el fondo de la celda y, posteriormente, en busca de mejoras, como la introducida por Boutin \& Trembay ${ }^{[4]}$ en 1960, se patentaron nuevos equipos, "las columnas de flotación", usando dispersores porosos flexibles, ubicados en el fondo del dispositivo.

Con el transcurso del tiempo, la flotación ha extendido su uso a aplicaciones no minerales, tales como separación de metales iónicos, grasas, aceites y tinta de papel reciclado. La flotación es un proceso físico, versátil, basado en propiedades de superficie ${ }^{[4]}$, donde las burbujas de gas (aire) son el medio de transporte de las especies a separar.

La flotación iónica es una técnica que hace uso de las propiedades especiales que caracterizan a las interfases para la concentración de iones u otras entidades con carga eléctrica, contenidos en soluciones acuosas ${ }^{[5]}$, mediante la alteración de las condiciones químicas del medio ${ }^{[5]} \mathrm{y}$, adicionando colectores adecuados (catiónicos [+] o aniónicos [-], según sea el catión o anión a colectar), la sustancia disuelta, se combina con el colector formando un producto organometálico soluble, que contiene sitios hidrofóbicos proporcionados por la cadena hidrocarbonada del colector ${ }^{[6]}$, que se puede adsorber a una burbuja, flotar hasta la superficie y concentrarse respecto al medio acuoso original.

La flotación iónica es un proceso interactivo que depende, tanto de condiciones químicas: concentración de colector, operacionales, Jg, Jl y de las propiedades de la dispersión: gas retenido, $\varepsilon_{\mathrm{g}}$, diámetro de burbuja, Db, como del flujo de superficie especifica de burbujas, $\mathrm{Sb}^{[5]}$, además de factores mecánicos como la geometría y el arreglo de los dispersores de burbujas en el equipo de flotación, estos últimos, considerados en el sistema de flotación como el corazón del proceso $^{[7]}$.

El gas retenido, $\varepsilon_{\mathrm{g}}$, puede estimarse por varios métodos. El usado en este trabajo de investigación fue por diferencias de presión con su ecuación más sencilla (Ec. (1)), en sistemas aire - agua - espumante ${ }^{[4,}$ 5,8 y 9 ].

$$
\varepsilon_{g}=\frac{\Delta P}{\Delta H} * 100
$$

El Sb o flujo de área superficial de burbujas representa, físicamente, el área superficial específica de burbujas disponible para llevar a cabo el proceso de captura de las especies ${ }^{\left[4 y^{5}\right]}$. Obtenido de la ecuación (2).

$$
S b=\frac{6 J g}{D b}
$$

\section{METODOLOGÍA EXPERIMENTAL}

Los experimentos se llevaron a cabo en una celda de flotación, construida de acrílico transparente de 19,1 x 19,1 cm de sección, por 33,5 cm de altura. La figura 1 muestra la representación esquemática. En una de las paredes laterales de la celda se instalaron dos manómetros de presión de agua, separados entre sí $20 \mathrm{~cm}$. Se colocó un vertedero en el rebosadero de la celda, para colectar la espuma. La alimentación, se ubicó en una pared opuesta a la salida de colas, ambas cerca del fondo de la celda. El flujo y descarga de líquido, se regularon con dos bombas peristálticas (una para cada corriente de flujo), de rango de 0,0 a $8,0 \mathrm{l} / \mathrm{min}$, previamente calibradas.

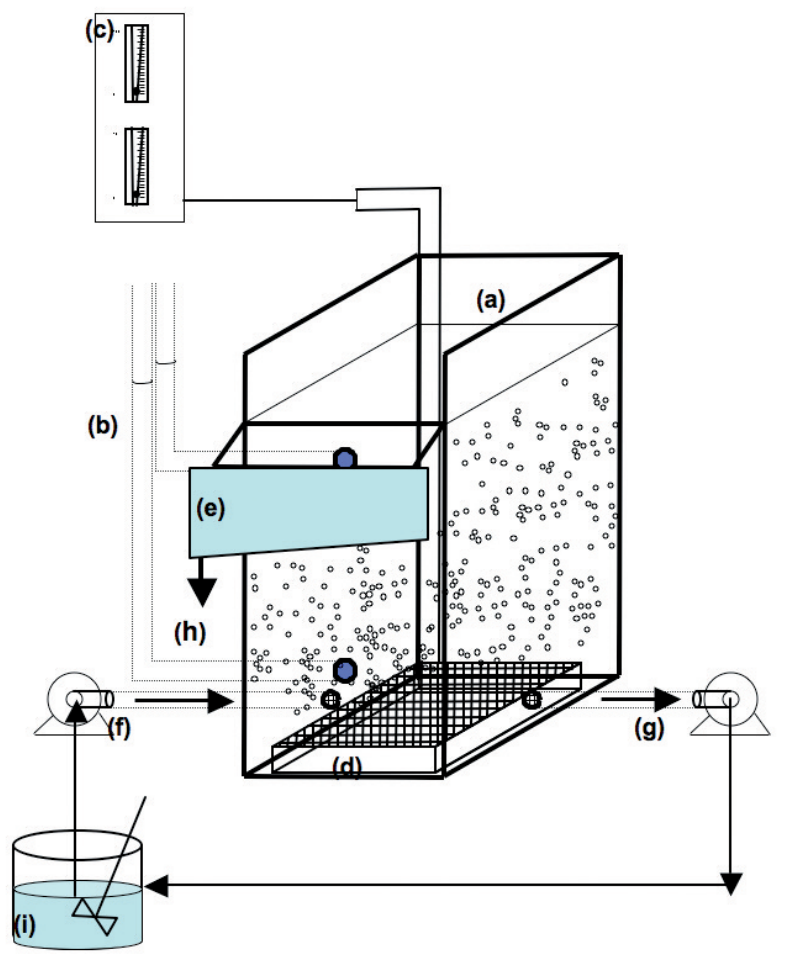

Figura 1. Representación esquemática del equipo de flotación: (a) Celda, (b) manómetros de presión de columna de agua, (c) Flujo metros, (d) dispersor poroso. (e) vertedero, (f) y (g) bomba peristáltica de alimentación y colas, respectivamente, (h) descarga de concentrado, (i) tanque de alimentación.

Figure 1. Schematic representation of the flotation device: (a) cell, (b) manometers of pressure column water, (c) flow meters, (d) sparger porous. (e) discharge, (f) and (g) peristaltic pumps, feed and tailings, respectively, (h) output concentrate, (i) tank of feed. 
El aire fue alimentado a la celda de flotación, individualmente, a través de dispersores porosos flexibles, dispuestos horizontalmente en la celda de flotación. La figura 2 presenta la disposición de los generadores de burbujas en la celda, correspondiendo la figura 2 a) al dispersor plano y la figura 2 b) al cilíndrico. Ambos están construidos de una sección de PVC perforada con diámetros de 0,1 cm y forrados con tela sintética (Fig. 2 c)). El aire fue regulado y controlado con dos rotámetros, uno de 0-10,0 1/min y otro de 0-100,0 1/min. Los rotámetros fueron calibrados previamente mediante un procedimiento de desplazamiento de columna de agua.

Para las pruebas de flotación iónica se preparó, en una etapa, una solución con 0,02 g/l de Cu (II), concentración por encima de lo marcado en la norma ecológica ambiental mexicana ${ }^{[10]}$, donde el límite máximo permisible de descarga para soluciones residuales es 0,005 g/l de cobre. Como espumante, se uso polipropilenglicol en dosificaciones de $0,03 \mathrm{~g} / \mathrm{l}$ y diferentes cantidades de colector, amil xantato de potasio $0,006,0,02,0,03,0,05$ y $0,06 \mathrm{~g} / \mathrm{l}$, dosificados los reactivos en el orden descrito. Las soluciones fueron agitadas durante toda la prueba a $4,2 \mathrm{~s}-1$, con una varilla de plástico montada en un rotor.

Para simular, de la mejor manera posible, una solución real, se uso agua del grifo y se evitó la presencia de partes metálicas, debido al riesgo de efectuar intercambio eléctrico. A las soluciones experimentales, se les dio un tiempo de acondicionamiento de 15 min. Posteriormente, se alimentó y descargó, continuamente, la solución en la celda, a una velocidad de flujo, Jl, de $0,19 \mathrm{~cm} / \mathrm{s}$ y mientras el gas fue inyectado a través del dispersor, la solución fue recirculada durante toda la prueba. Cada dos periodos de tiem- po de residencia (Ec. (3)), se muestrearon las corrientes de concentrado, colas y alimentación, tomando el tiempo de muestreo y pesando la muestra, para expresar los resultados en forma de un flujo másico, obteniendo la recuperación con la ecuación (4).

$$
\begin{gathered}
\tau=\frac{V z C}{Q I}\left(1-\varepsilon_{g}\right) \\
\% R=\frac{F M_{C}}{F M_{C}+F M_{T}} * 100
\end{gathered}
$$

Para las pruebas de flotación iónica multi etapas se procedió similarmente, solo que, esta vez, la solución no se retroalimento. El flujo de salida, se depositó en un tanque independiente al de alimentación, así también, para el concentrado. Una vez pasado todo el volumen inicial de la primera etapa, la descarga de la primera etapa se usó como alimentación para la segunda etapa de flotación y, así, sucesivamente, hasta una quinta etapa, tal como se aprecia en la figura 3, obteniendo la recuperación con la ecuación (5).

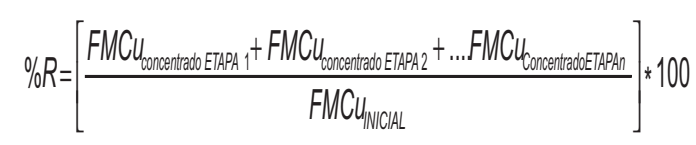

evaluando, además, los efectos de Jg, Jl, Db y Sb en función de la recuperación. De la literatura, se desprende que Jg, representa la velocidad superficial de gas, $\mathrm{Jg}=\mathrm{Qg} / \mathrm{Ac}$, expresada en $\mathrm{cm} / \mathrm{s}^{[4}$ y 8$]$. Jl es la velocidad superficial de líquido, Jl=Ql/Ac. En los

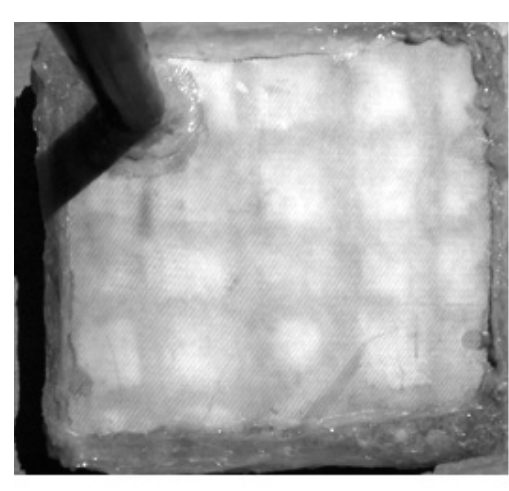

a)

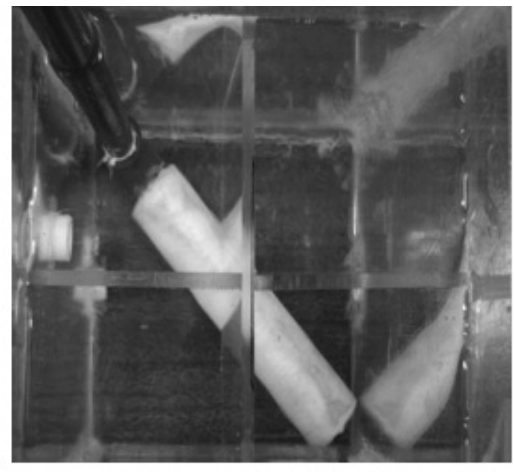

b)

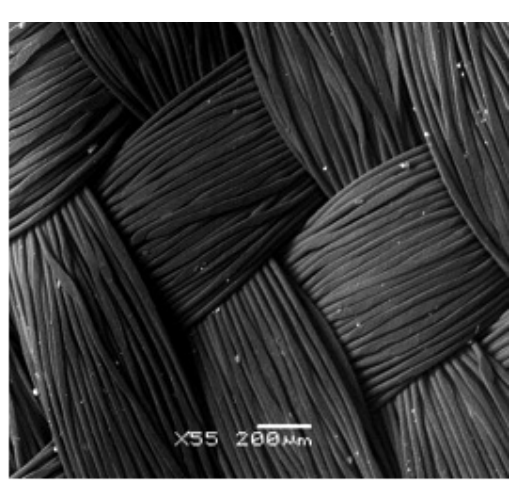

c)

Figura 2. Disposición de los sistemas de dispersión en la celda de flotación vista de planta; a) dispersor plano, b) cilíndrico y c) micrografía de MEB de las fibras de la tela, usada.

Figure 2. Disposition of the dispersion system, in the flotation cell, plant view; A) flat sparger, b) cylindrical and c) photomicrography MEB of the fibers of cloth used. 


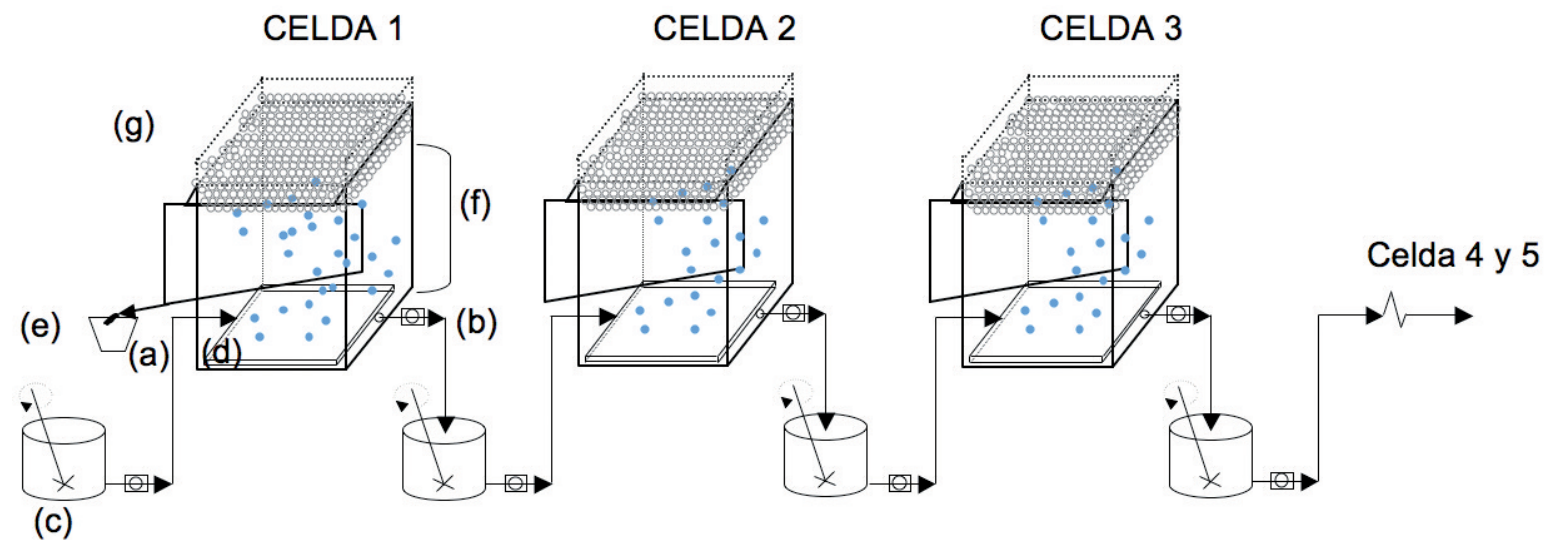

Figura 3. Arreglo esquemático del banco de celdas de flotación con dispersores flexibles porosos. (a) alimentación. (b) colas (descarga). (c) tanque Acondicionador. (d) dispersor poroso de tela (e) descarga del concentrado. (f) zona de colección. (g) cama de espuma.

Figure 3. Schematic representation the bank of flotation cell with sparger porous flexible. (a) feed. (b) tailings. (c) aconditioner tank. (d) sparger porous of cloth. (e) output concentrate. (f) collection zone $(g)$ froth depth.

sistemas de flotación con dispersores porosos, existen diferentes corrientes, $\mathrm{Jl}_{\mathrm{A}}, \mathrm{Jl}_{\mathrm{C}}, \mathrm{Jl}_{\mathrm{T}}{ }^{[4 \mathrm{y} 5]}$. El Diámetro de burbuja, $\mathrm{Db}$, se obtuvo mediante el procedimiento interactivo conocido como análisis de arrastre "Drift Flux" ${ }^{[11-13]}$, usando datos de gas retenido y velocidades relativas de fase, Jg y Jl. Cabe mencionar que este método provee datos globales del Dd, considerando un flujo homogéneo de burbujas en el equipo de flotación. Otros métodos, que bien podrían describir el tamaño de burbuja tomando en cuenta distribución de burbujas y, por tal, velocidades de fase, es el descrito por Finch y colaboradores, en la técnica viewing chamber ${ }^{[14-16]}$. Otro procedimiento es mediante la captura de imágenes de burbujas en el equipo de flotación. Sin embargo, es difícil de aplicar cuando se tienen grandes velocidades de flujo de gas ${ }^{[13]}$.

Para determinar la constante cinética de flotación, se extrae de la bibliografía la ecuación (6): para un reactor de mezclado perfecto donde hay una distribución del tiempo de residencia (DTR), la concentración es la misma en todo el reactor ${ }^{[4]}$. Cabe mencionar que, dicha ecuación se aplica cuando se tiene un flujo constante, homogéneo y uniforme de tamaños de burbujas, caracterizado por una relación lineal del gas retenido, vs. la velocidad superficial de gas ${ }^{[4]}$.

$$
R=1-\exp (-\kappa t)
$$

donde, t se obtiene de la ecuación (3).

\section{RESULTADOS Y DISCUSIÓN}

\subsection{Pruebas preliminares, distribución de tiempo de residencia (DTR)}

Estas, se llevaron a cabo para determinar el comportamiento de mezclado en la celda de flotación con dispersores. Las pruebas consistieron en inyectar un volumen de 0,5 1 de una solución saturada de $\mathrm{KCl}$ en la corriente de alimentación. El líquido fue retroalimentado durante todo el experimento y se monitoreo la conductividad eléctrica de la solución durante 9 min en la descarga (colas), usando una celda de flujo de conductividad eléctrica, descrita en la literatura ${ }^{[17}$ y 18$]$, tomando una lectura cada $1 \mathrm{~s}$, empleando una tarjeta de adquisición de datos. La figura 4 muestra los resultados obtenidos para el dispersor plano, a diferentes velocidades superficiales de líquido, Jl. Las curvas encontradas son similares a las típicas de un reactor tipo de mezclado perfecto ${ }^{[19]}$. Resultados análogos se presentan para ambas geometrías de dispersión (plano y cilíndrico). Se observó, que el tiempo de mezclado perfecto de la solución disminuye con el Jl. Con base en estos resultados, se utilizó la ecuación (6) para el cálculo de la constante cinética de flotación aparente.

\subsection{Flotación iónica de Cu (II) en una etapa. Dispersor plano.}

La figura 5 a) muestra el porcentaje de recuperación, vs. la velocidad superficial de gas, Jg, con Jl de 0,19, 


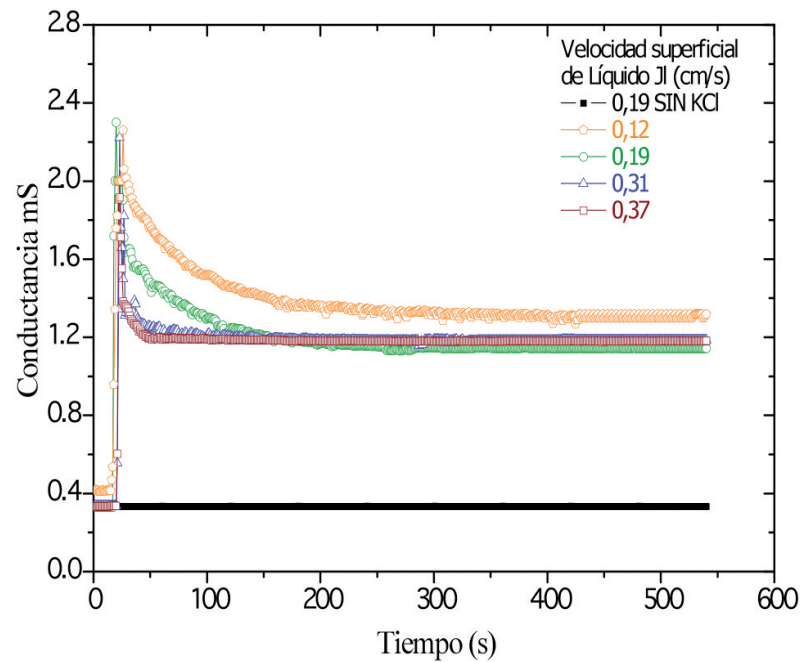

Figura 4. Distribución del tiempo de residencia del líquido, dispersor plano, 0,03 g/l de espumante, Jg constante de 0,8 . variando la velocidad superficial de líquido.

Figure 4. Residence time distributions for liquid, flat sparger, surfactant $0.03 \mathrm{~g} / \mathrm{l}, \mathrm{Jg} 0.8$. at several superficial liquid velocities $\mathrm{Jl}$.

$0,03 \mathrm{~g} / \mathrm{l}$ de espumante, para las concentraciones de $0,02 \mathrm{~g} / \mathrm{l}$ y $0,06 \mathrm{~g} / \mathrm{l}$ de xantato amílico de potasio, usando el dispersor plano. Se presentan, solamente, estas dos curvas como objeto de comparación. El resto de las concentraciones de xantato experimentadas presentaron un comportamiento entre la curva superior e inferior. Se observó, que el incremento de la cantidad de colector en el sistema disminuye, considerablemente, el porcentaje, en peso, de recuperación de cobre, siendo la máxima recuperación alcanzada de $56 \%$ (con $0,02 \mathrm{~g} / \mathrm{l}$ de xantato). Esto, debido al efecto de la formación de micelas y la nula captura de los iones acomplejados con el colector, por tanto, disminuyendo la recuperación. La condición del Jg juega un papel muy importante: de la figura 5 a) se observa que, velocidades de gas superiores a 0,8 disminuyen las recuperaciones para ambas concentraciones de colector usadas, esto es, por efecto de las corrientes de circulación de las fases continua y dispersa causadas por una distribución irregular de burbujas gas en la celda de flotación. De mediciones puntuales de conductividad eléctrica de la dispersión, en nueve sitios diferentes, se pudo comprobar que no hay buena distribución de gas retenido, por lo que las burbujas de gas no son homogéneamente distribuidas en la celda, localizándose zonas con diferencias en la densidad relativa de las fases involucradas y provocando condiciones hidrodinámicas desfavorables para la concentración de iones por flotación iónica, especialmente a valores elevados de Jg. Por otro lado, el e estimado por diferencias de presión (Ec. (1)), presenta valores globales y no permite conocer la distribución de las burbujas en el sistema, en contraste con el $\mathrm{e}_{\mathrm{g}}$ estimado con sensores de conductividad eléctrica[17 y 18]. Con mayores Jg, el porcentaje de gas retenido aumenta (Fig. (5 b)). Sin embargo, esto no contribuye en lograr mejores recuperaciones y disminuye, aun más, para el sistema con 0,06 g/l de colector.

De los datos del porcentaje de $\mathrm{e}_{\mathrm{g}}$, obtenidos para los sistemas con $0,03 \mathrm{~g} / \mathrm{l}$ de espumante y 0,02 y $0,06 \mathrm{~g} / \mathrm{l}$
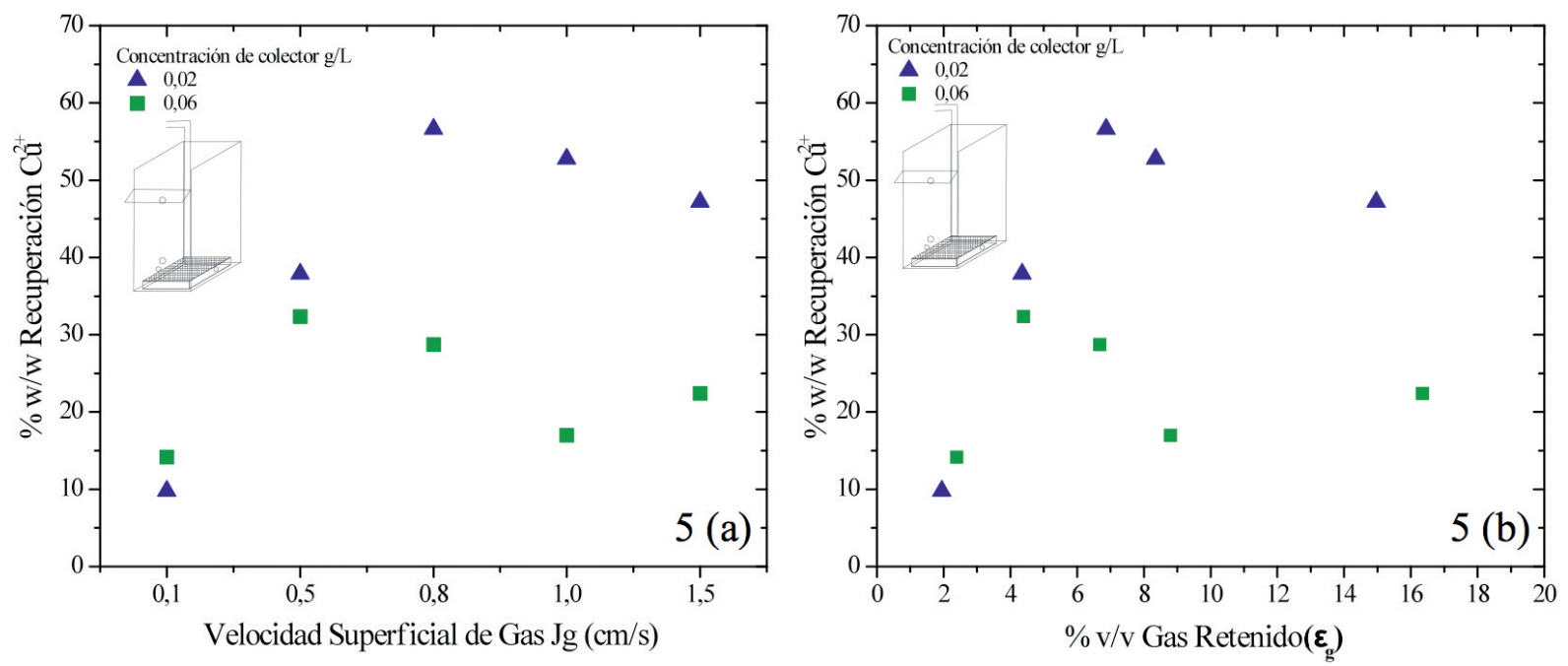

Figura 5. a) Comportamiento de los parámetros de la dispersión (Jg \& $\left.\varepsilon_{\mathrm{g}}\right)$. b) su efecto en él \% w/w de recuperación de cobre.

Figure 5. a) Behavior of the dispersion parameters $\left(\mathrm{Jg} \& \varepsilon_{g}\right)$. b) its effect on \% w/w copper recovery. 
de colector para el sistema con el dispersor plano (Fig. 6 a)), se observó una adecuada similitud, por lo que una cantidad en exceso de xantato, no altera la condición del gas retenido. Sin embargo, como se aprecia en la figura $6 \mathrm{~b}$ ), la cual presenta los resultados de los valores de gas retenido para los sistemas con espumante $0,03 \mathrm{~g} / \mathrm{l}$ sin y con colector (para ambas concentraciones de xantato), la presencia de xantato influye notablemente en el $\varepsilon_{\mathrm{g}}$, siendo mayor para los sistemas sin colector, especialmente a Jg superiores a 0,8 , por lo que su presencia afecta, tanto al $\varepsilon_{\mathrm{g}}$ como a la recuperación, cuando se tienen altas concentraciones, debido a la formación de micelas, las cuales inhiben la separación de los complejos formados.

La figura 7 a) y b) muestra el flujo de área superficial específica de burbujas, Sb, disponible para llevar acabo el proceso de separación de las especies acomplejadas. Se observó que, valores mas elevados de Jg contribuyen a generar un mayor $\mathrm{Sb}$ en la celda, para ambas concentraciones de xantato. Esto, en
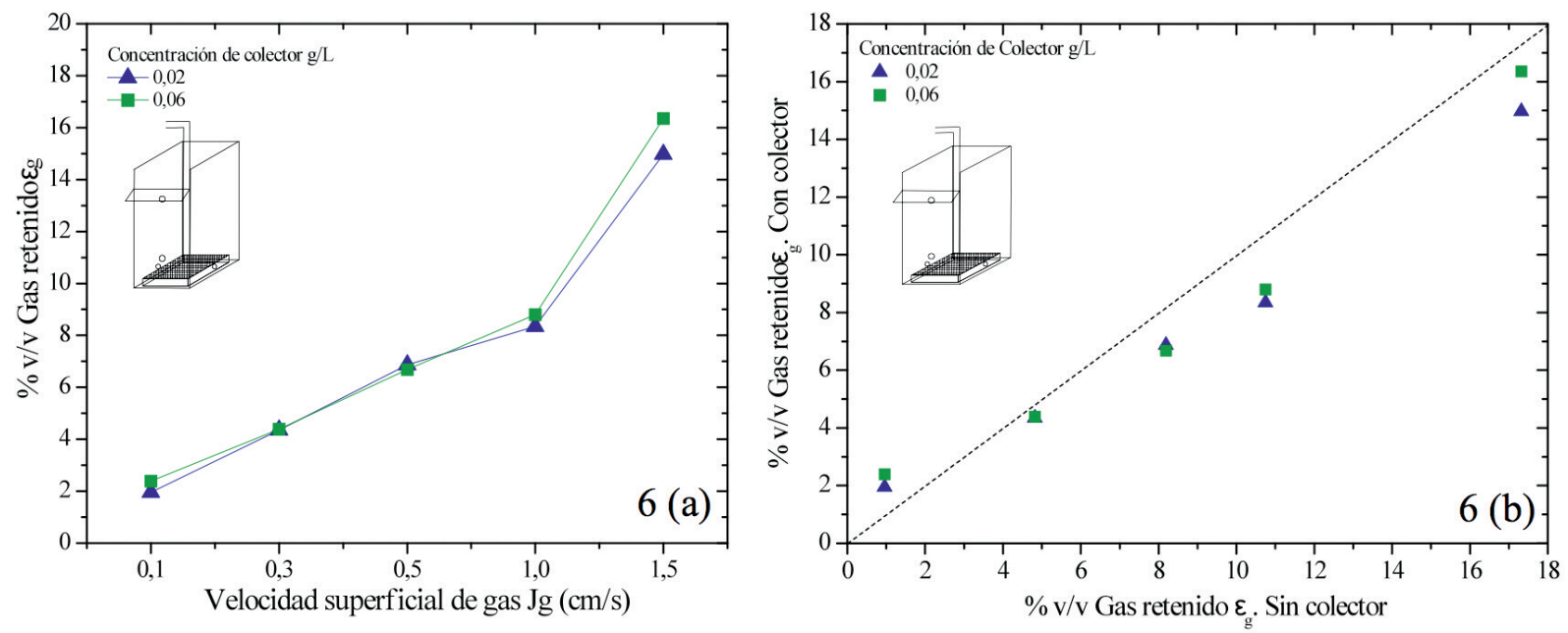

Figura 6. a) \% v/v de gas retenido vs. velocidad superficial de gas para las concentraciones de xantato amílico de potasio $\mathrm{C}_{5} \mathrm{H}_{11} \mathrm{OCS}_{2} \mathrm{~K}$ de 0,02 y $0,06 \mathrm{~g} / \mathrm{l}$. b) Gas retenido con colector $\mathrm{Vs}$. $\varepsilon_{\mathrm{g}}$ con, sólo, espumante.

Figure 6. a) $\%$ v/v gas holdup vs. superficial gas velocity with 0.02 y $0.06 \mathrm{~g} / \mathrm{l}$. of potassium amylxanthate $\mathrm{C}_{5} \mathrm{H}_{11} \mathrm{OCS}_{2} \mathrm{~K}$. b) gas holdup with collector Vs. gas holdup with only surfactant.
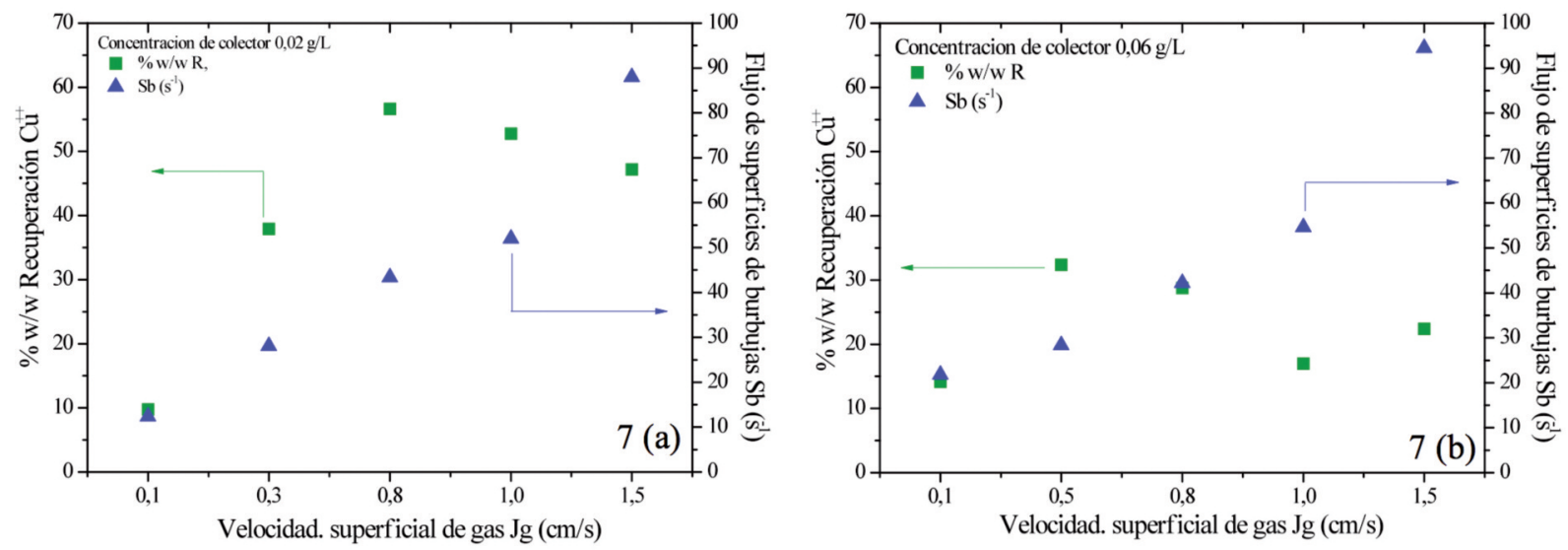

Figura 7. a) y b) \% w/w recuperación de cobre y flujo de área superficial de burbujas Sb Vs. velocidad superficial de gas, dispersor plano, para el sistema con 0,02 y 0,06 g/l de xantato amílico de potasio, con $0,03 \mathrm{~g} / \mathrm{l}$ de espumante.

Figure 7. a) y b) \% w/w recovery $\mathrm{Cu}$ (II) and bubble surface area flux Sb Vs superficial gas velocity, flat sparger, system with 0.02 and $0.06 \mathrm{~g} / \mathrm{l}$ of potassium amylxanthate, with $0.03 \mathrm{~g} / \mathrm{l}$ of surfactant. 
flotación de minerales, normalmente significaría una mayor probabilidad de colisión burbuja - especie y, por tanto, mayor captura. Sin embargo, para la flotación iónica, esto, no resulto así en celdas con dispersores, ya que con valores de Sb mas altos, el flujo homogéneo y uniforme de burbujas cambia a un régimen turbulento, presentándose, generalmente, a $\mathrm{Jg} \leq 0,8$, causando que las especies colectadas se liberen y regresen a la fase acuosa. Además, presentándose distribución de tamaños de burbujas y zonas con amplias diferencias en densidades relativas, produciéndose mayor grado de corrientes de circulación y mezclado del líquido y gas, afectando, en la eliminación del cobre de la solución, así como también en la constante cinética de flotación aparente $k$.

La figura 8 a) y b) presenta los resultados obtenidos de la constante cinética de flotación aparente, $k$, dispersor plano, para las concentraciones de colector de 0,02 y 0,06 g/l, respectivamente. Se encontró que $k$ tiene un comportamiento lineal con: la recuperación, $\mathrm{Sb}$, y los parámetros de la dispersión. Esto, hasta Jg $\leq 0,8\left(\varepsilon_{g}=6,9 ; \mathrm{Sb}=43,0\right)$, valores en los que se da el cambio de régimen de un flujo burbujas, de uniforme a turbulento, caracterizado por la pérdida de linealidad de $\varepsilon_{g}$ contra Jg. En estas figuras se observa que hay menores velocidades de transferencia del complejo Cu-xantato, de la zona de colección a la zona espuma, con $\mathrm{Sb} \leq 43,0$ para la concentración de $0,02 \mathrm{~g} / \mathrm{l}$. El tiempo de residencia del continuo en la celda de flotación disminuye con el Jg. Para las pruebas realizadas con 0,06 g/l de xantato, se observó mayor variación en el sistema, obteniendo recuperaciones de 28,8\%, en peso, $4,4 \%$ de $\varepsilon_{\mathrm{g}}$, Sb 33,0. Perdiéndose la linealidad con Jg de 0,5.

\subsection{Flotación iónica de $\mathrm{Cu}$ II en una etapa. Dispersor cilíndrico}

Los resultados encontrados para el sistema con el dispersor cilíndrico se presentan en la figura 9, donde se representa el porcentaje, en peso, de recuperación de $\mathrm{Cu}$ (II), vs. Jg. Para el sistema con 0,02 y 0,06 g/l de colector, $0,03 \mathrm{~g} / \mathrm{l}$ de espumante, se observó, para la concentración de 0,02, una máxima recuperación de $68 \%$, cuando Jg es 0,8. Mayores valores de Jg provocan que la recuperación disminuya, tal como para el dispersor plano, encontrando similitud en este aspecto. Para las pruebas con $0,06 \mathrm{~g} / \mathrm{l}$, se obtuvo una recuperación significativamente menor, tal como se observa en la grafica. Esto, se debe a la menor cantidad de gas retenido para el sistema con $0,06 \mathrm{~g} / \mathrm{l}$ (Fig. 10). Similar comportamiento se aprecia cuando se representa el porcentaje, en peso, de recuperación, vs. el porcentaje, en volumen, de gas retenido.

La figura 10 muestra el porcentaje de gas retenido para los dispersores plano y cilíndrico, con concentraciones de 0,02 y 0,06 g/l de colector y 0,03 g/l de espumante. Se observó que, no obstante la similitud de $e_{\mathrm{g}}$ para ambos dispersores (con 0,02 g/l), se obtiene una mayor recuperación con el dispersor cilíndrico. Esto, producto de observaciones experimentales, es debido a la menor intensidad de corrientes de circulación y mezclado, provocado por la mayor generación de superficies de burbujas en el dispersor cilíndrico en comparación con el plano.

Cabe destacar que, durante las pruebas de flotación, el aire inyectado en el dispersor no generó burbujas en toda el área superficial de este, especialmente a bajas velocidades superficiales de gas, Jg.
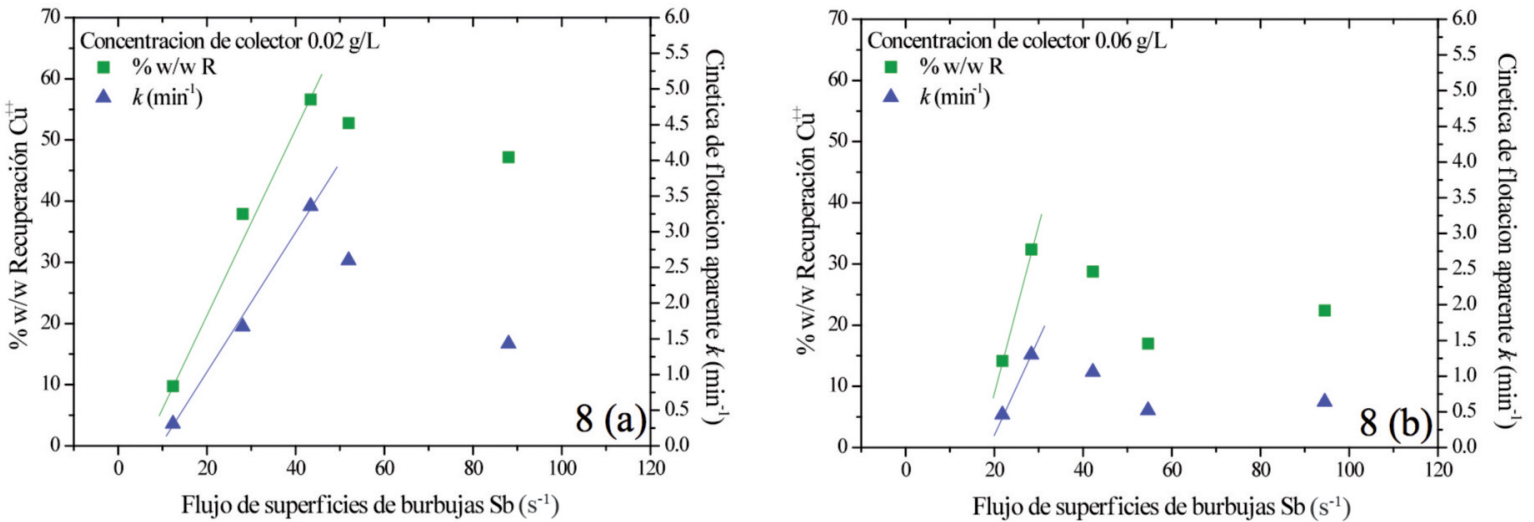

Figura 8. a) y b) \% w/w recuperación de cobre y la constante cinética de flotación aparente $\mathrm{k}\left(\mathrm{min}^{-1}\right)$, vs. flujo de área superficial de burbujas Sb, dispersor plano, con 0,02 y 0,06 g/l de xantato amílico de potasio respectivamente, $0,03 \mathrm{~g} / \mathrm{l}$ de espumante.

Figure 8. (a) and (b) \% w/w recovery copper and apparent flotation rate constant $k\left(m^{-1}{ }^{-1}\right) \mathrm{Vs}$. bubble surface area flux Sb, flat sparger, system with 0.02 and $0.06 \mathrm{~g} / \mathrm{l}$ of potassium amylxanthate respectively. 


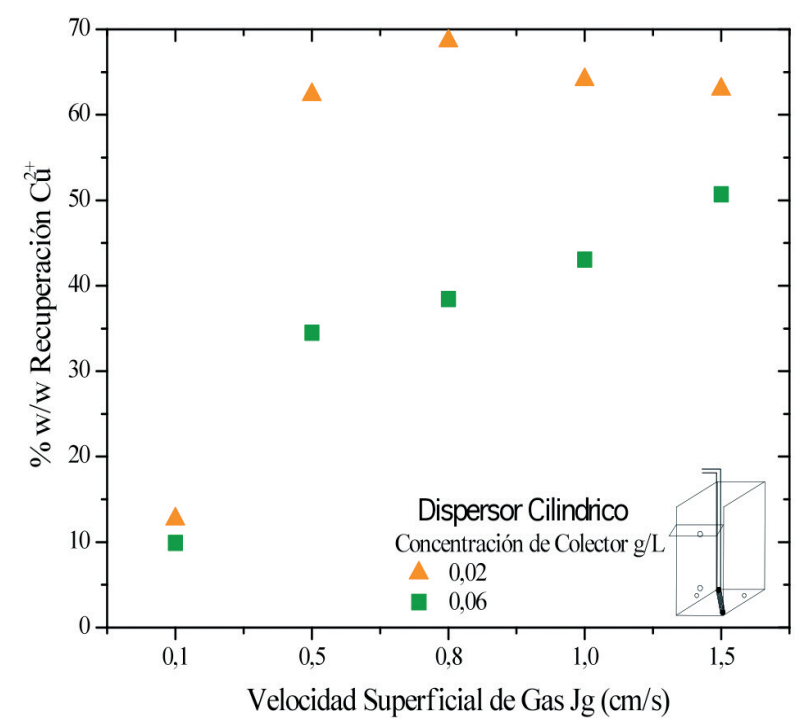

Figura 9. a) y b) \% w/w recuperación de Cu (II) Vs. velocidad superficial de gas, dispersor cilíndrico, para el sistema con 0,02 y $0,06 \mathrm{~g} / \mathrm{l}$ de xantato amílico de potasio, 0,03 $\mathrm{g} / \mathrm{l}$ de espumante.

Figure 9. (a) y (b) \% w/w recovery $\mathrm{Cu}$ (II) Vs superficial gas velocity, cylindrical sparger, system with 0.02 and $0.06 \mathrm{~g} / \mathrm{l}$ of potassium amylxanthate, $0.03 \mathrm{~g} / \mathrm{l}$ of surfactant.

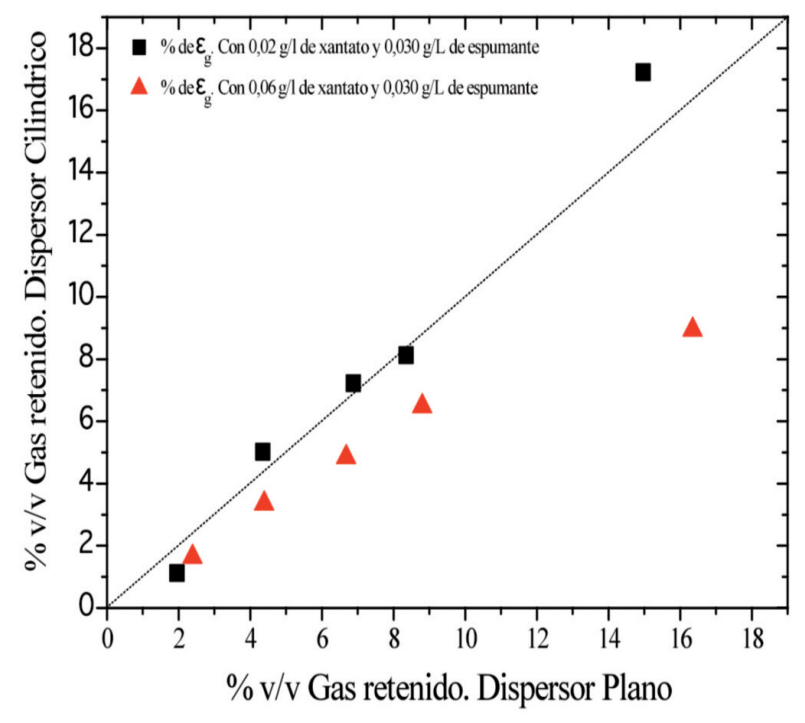

Figura 10. \% v/v de gas retenido dispersor cilíndrico vs. $\%$ v/v de gas retenido dispersor plano. Para las concentraciones de colector de 0,02 y $0,06 \mathrm{~g} / \mathrm{l}$ de xantato, $0,03 \mathrm{~g} / \mathrm{l}$ de polipropilenglicol.

Figure 10. \% v/v de gas holdup cylindrical sparger vs. \% v/v de gas holdup flat sparger, with 0.02 and $0.06 \mathrm{~g} / \mathrm{l}$ xanthate concentration and $0.03 \mathrm{~g} / \mathrm{l}$ of polipropylenglicol.
Para el dispersor cilíndrico y con una concentración de 0,06 g/l de xantato, el gas retenido es significativamente menor al del dispersor plano. Sin embargo, se logran mayores recuperaciones con el primero, debido a los efectos anteriormente mencionados.

La disminución del porcentaje, en volumen, de $\varepsilon_{\mathrm{g}}$, para el sistema con $0,06 \mathrm{~g} / \mathrm{l}$ de colector, causa un incremento en el diámetro de burbuja, debido a la mayor velocidad de ascenso de estas burbujas y, por ello, una menor probabilidad de colisión burbuja especie y mínima recuperación del complejo $\mathrm{Cu}$ xantato. La figura 11 muestra los valores de $\mathrm{Db}$ (cm.), vs. la velocidad superficial de gas, Jg, para el sistema con el dispersor cilíndrico, con concentraciones de colector de 0,02 y 0,06 g/l, así como 0,03 $\mathrm{g} / \mathrm{l}$ de espumante. Cabe mencionar que los valores Db se estimaron, como primera aproximación, con el análisis de arrastre "Drift Flux". Sin embargo, este modelo no considera distribuciones de tamaño de burbujas y velocidades de fase.

La generación de diámetros de burbuja de menor tamaño, está estrechamente relacionada con el porcentaje de recuperación de cobre y, esto, a su vez, con la velocidad de transferencia, $k$, de la especie metal-xantato de la zona de colección a la cama de espuma, tal como se observa en la figura 12 a) y b), donde se representa el porcentaje, en peso, de

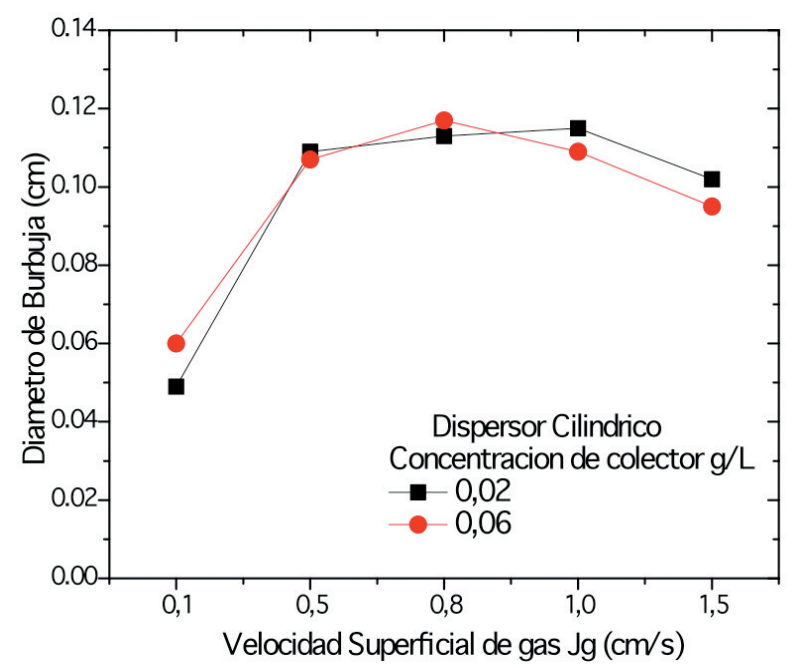

Figura 11. Diámetro de burbuja $(\mathrm{cm})$ vs. velocidad superficial de gas Jg, dispersor cilíndrico, para el sistema con 0,02 y $0,06 \mathrm{~g} / \mathrm{l}$ de xantato amílico de potasio, $0,03 \mathrm{~g} / \mathrm{l}$ de espumante.

Figure 11. Diameter bubble (cm) vs. superficial gas velocity, cylindrical sparger, system with 0.02 and $0.06 \mathrm{~g} / \mathrm{l}$ of potassium amylxanthate, $0.03 \mathrm{~g} / \mathrm{l}$ of surfactant. 
CINÉTICA DE SEPARACIÓN DE CU (II) POR TÉCNICAS DE FLOTACIÓN IÓNICA, EN CELDAS CON DISPERSORES FLEXIBLES KINETICS OF CU (II) SEPARATION BY ION FLOTATION TECHNIQUES, IN CELLS WITH FLEXIBLE SPARGERS
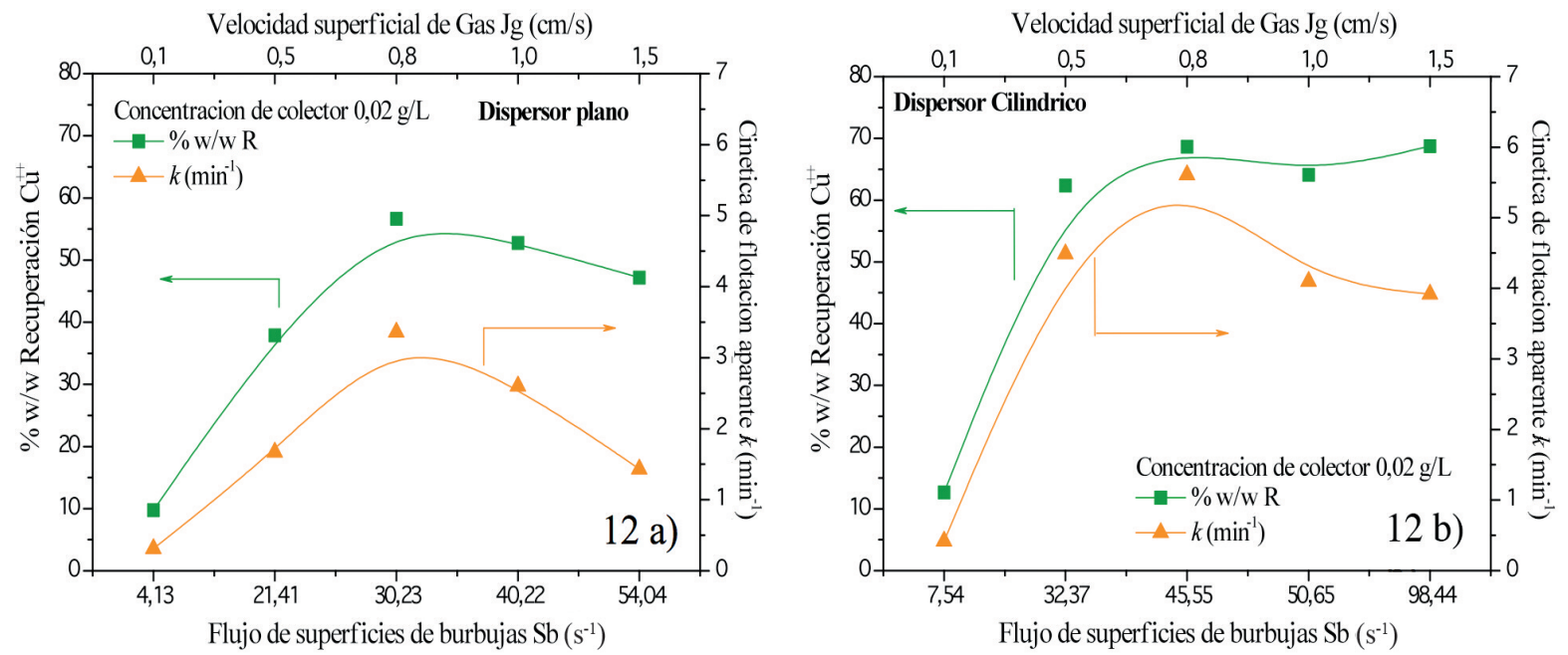

Figura 12. a) \% w/w recuperación de cobre y la constante cinética de flotación aparente, $\mathrm{k}\left(\mathrm{min}^{-1}\right)$, vs. velocidad superficial de gas $\mathrm{Jg}(\mathrm{cm} / \mathrm{s})$, b) flujo de área superficial de burbujas $\mathrm{Sb}$; a) dispersor plano; b) dispersor cilíndrico.

Figure 12. a) $\% \mathrm{w} / \mathrm{w}$ recovery copper and apparent flotation rate constant $\mathrm{k}\left(\mathrm{min}^{-1}\right) \mathrm{Vs}$. superficial gas velocity Jg (cm/s); b) bubble surface area flux Sb; a) flat sparger; b) cylindrical sparger.

recuperación y la constante cinética de flotación aparente, vs. la velocidad superficial de gas para el sistema con 0,02 y 0,06 g/l de colector respectivamente.

Con valores mas elevados de Jg, el porcentaje, en peso, de recuperación aumenta (Fig. (12 a)), debido a la disminución de $\mathrm{Db}$, causando que $\mathrm{Sb}$ se incremente con cada valor de Jg. De la misma manera, la constante de flotación aparente es mayor. Esto, hasta donde se observa un comportamiento lineal de la recuperación, con los parámetros de la dispersión de gas, Jg, $\varepsilon_{\mathrm{g}}$ y $\mathrm{Db}$ de 0,8 cm/s, 8,7 \% y $0,1 \mathrm{~cm}$, respectivamente.

De la figura 12 b), con Jg 1,5 y Sb 98,44, se observó que la recuperación aumenta ligeramente, debido a una aparente competencia entre los parámetros de la dispersión y la hidrodinámica del sistema, donde una mayor superficie especifica de burbujas (Sb), disponible para la captura de especies hidrofóbicas, supera las corrientes de circulación y mezclado, logrando porcentajes de recuperación similares a los obtenidos para Jg $\leq 0,8$ y Sb 45,5.

La figura $12 \mathrm{~b}$ ) presenta los resultados del porcentaje, en peso, de recuperación de cobre y la constante cinética de flotación aparente, $k,{ }^{v s}$. el valor de $\mathrm{Sb}$ para el dispersor cilíndrico. Se observó un comportamiento lineal entre estos parámetros. Esto, hasta Jg " 0,8 donde, debido a las corrientes de circulación, se produce una menor velocidad de transferencia del ion metálico de la solución a la espuma (concentrado), impidiendo el flote hasta la superficie.

\subsection{Flotación iónica multi etapas. Dispersor plano y cilíndrico}

En esta sección se presenta el efecto de la velocidad superficial de gas, Jg, en la recuperación de cobre, usando el dispersor plano (Fig. 13 a)) y dispersor cilíndrico (Fig. 13 b)), usando 0,02 g/l de xantato amílico de potasio y $0,03 \mathrm{~g} / \mathrm{l}$ de espumante. Se observó que la extracción acumulativa aumentó con el número de etapa, logrando máximas separaciones, de alrededor del $92 \%$, para valores de Jg de 0,5 y 0,8 con el dispersor plano. Esto permite dejar la solución residual en una última etapa (quinta) con bajas concentraciones de cobre, por debajo de los límites permisibles para su descarga según la norma ecológica mexicana, mostrando la efectividad del proceso de flotación. Cabe mencionar las ventajas económicas de este proceso respecto a otros tradicionales, que radican en la capacidad de procesamiento de grandes volúmenes de solución en tiempos relativamente cortos y con pocos costos de inversión.

De la figura 13 a) y b) se observa, sin embargo, que cuando se emplean valores de Jg más altos $(1,0$ y $1,5)$ las recuperaciones disminuyen por efecto de la turbulencia del sistema, corrientes de circulación y mezclado, que son consecuencia natural de un reactor de mezclado perfecto.

Los resultados para el sistema con el dispersor cilíndrico (Fig. (13 b)) muestran que a un valor de Jg de 0.5 se obtienen las extracciones de cobre más bajas, aun para la quinta etapa, la cual es de $59 \%$, 

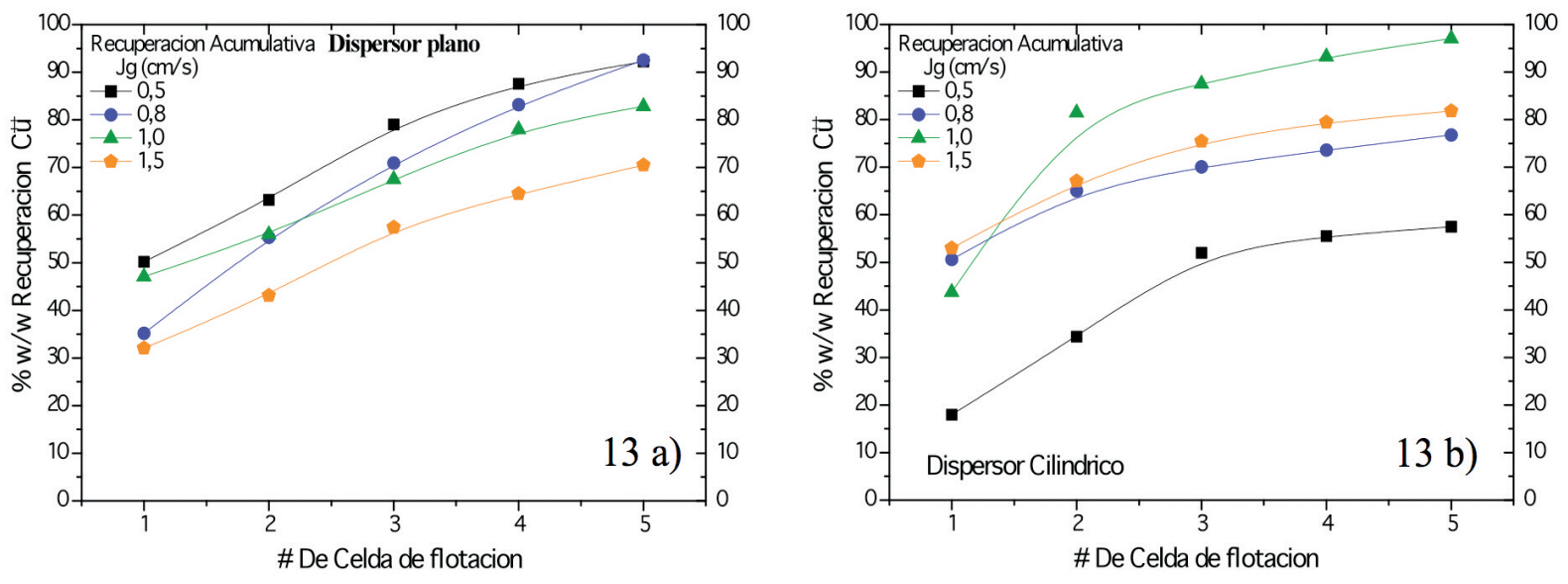

Figura 13. \% w/w recuperación acumulativa de Cu (II) Vs. numero de celda de flotación, diferentes velocidades superficiales de gas Jg, a) dispersor plano b) dispersor cilíndrico.

Figure 13. \% w/w accumulative recovery Cu (II) vs. flotation cell number at several superficial gas velocities Jg, a) flat sparger, b) cylindrical sparger.

debido a la poca aireación (cantidad de burbujas) en la mayor parte de la sección de la celda, causada por la geometría del sistema de dispersión, que solo aireó la parte central diagonal. Mientras que para los valores de Jg de 0,8 y 1,0, se logró 97 \% de recuperación en la quinta etapa, lo cual mejora notablemente la separación del ion metálico. Sin embargo, con un valor de Jg de 1,5 se genera mayor cantidad de burbujas, lo que origina mayor turbulencia, mezclado y coalescencia de burbujas, afectando y disminuyendo la recuperación.

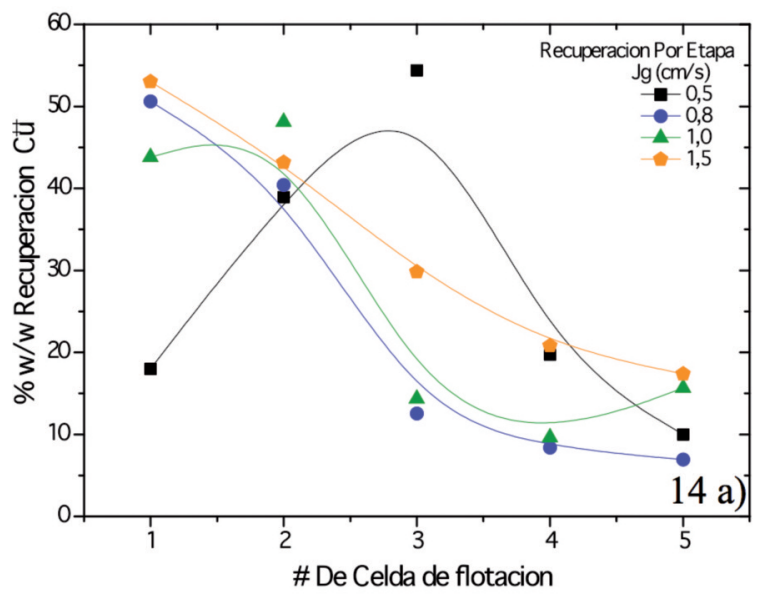

La recuperación en cada etapa, tuvo en común su disminución con el número de esta figura 14 a), esto es, atribuido a la modificación de las condiciones físico químicas de la solución, donde la tensión superficial aumenta con el número de etapa, estimada mediante un procedimiento de formación de la burbuja, descrito en la literatura[20], debido a la remoción de moléculas de espumante y colector de la celda, que junto con el cobre derraman por el rebosadero. La modificación de la tensión superficial causo la disminución del porcentaje de gas retenido e, inherentemente, el ta-

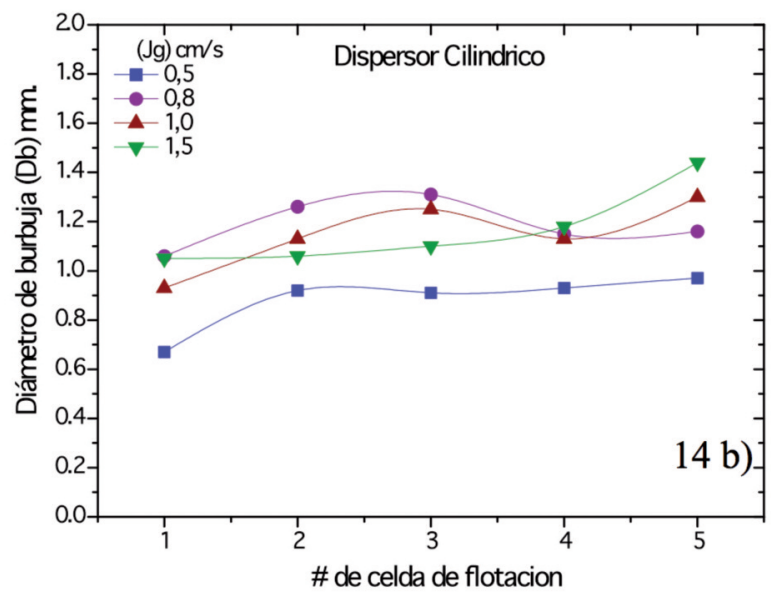

Figura 14. a) \% w/w recuperación por etapa de Cu (II). b) diámetro de burbuja Vs. numero de celda de flotación, a diferentes velocidades superficiales de gas Jg, dispersor cilíndrico.

Figure 14. a) \% w/w stage recovery $\mathrm{Cu}$ (II). b) bubble diameter vs. flotation cell number at several superficial gas velocities Jg, cylindrical sparger. 
maño de burbuja tiende a incrementar ligeramente con el número de etapa (Fig. 14 b)).

La figura 15 a) presenta el efecto de la velocidad superficial de líquido, Jl, en la recuperación de cobre, usando el dispersor plano. Se observa que la recuperación incrementa con el número de etapa de flotación y es ligeramente mayor para velocidades de líquido de 0,31 y 0,37 (6,8 y $8,1 \mathrm{l} / \mathrm{min})$. Esto se refleja en el tiempo de residencia del continuo disminuyendo con el incremento de Jl y, por tanto, se logran mayores recuperaciones en menores tiempos de procesamiento, tratando, además, un volumen considerablemente mayor. El tiempo de residencia aparente del continuo para los valores de Jl de 0,19, 0,31 y 0,37 , fueron $2,7,1,6$ y $1,3 \mathrm{l} / \mathrm{min}$ respectivamente, la disminución del tiempo de proceso, aumenta la velocidad de transferencia de las especies hidrofóbicas de la zona de colección a la zona de espuma. La figura 15 b) muestra los resultados para el dispersor cilíndrico. Se observa que un valor Jl de 0,31 permite incrementar la recuperación de: $78 \%$ con Jl de 0,19 a $90 \%$ con Jl de 0,31 . Todos estos resultados a un Jg constante de 0,8 , mientras que, para un incremento de $\mathrm{Jl}$ a 0,37 , las recuperaciones disminuyen drásticamente cayendo a solo $30 \%$ en una quinta etapa, por lo que para este tipo de generadores de burbujas y velocidades de liquido de 0,37 (1,3 l/min), incrementa las corrientes de circulación y mezclado en la celda, donde las burbujas no emergen a la superficie y son continuamente enviadas hacia el fondo de la celda, provocando, además, la liberación de especies debido a la turbulencia y coalescencia de burbujas, produciéndose que disminuya la separación de cobre por flotación.

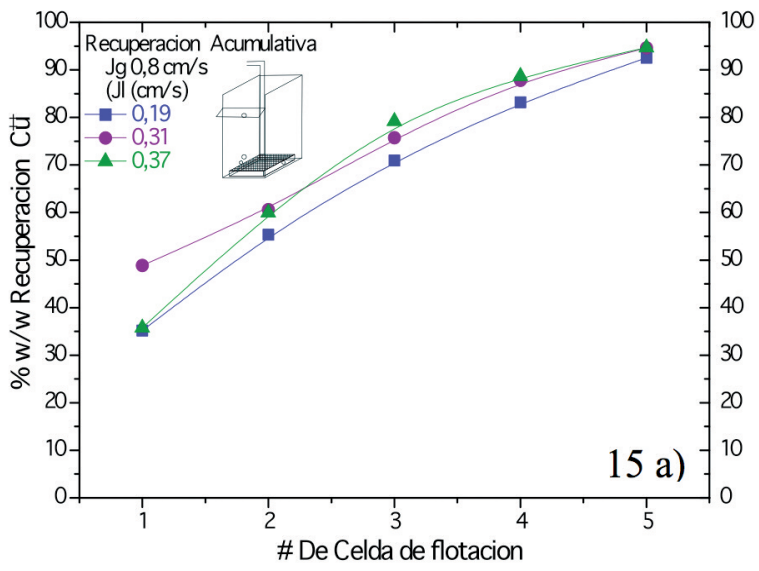

\section{CONCLUSIONES}

Se estudio la flotación iónica de cobre en una celda con dispersores porosos flexibles y usando reactivos orgánicos aniónicos, encontrándose que la eliminación del metal de soluciones sintéticas con cobre, se puede llevar a cabo, logrando en una sola etapa recuperaciones del 68 y $56 \%$ de separación con una concentración de xantato de 0,02 g/l, para los dispersores de burbujas cilíndrico y plano, respectivamente. Mientras, para, sistemas multi etapas, cinco celdas, se lograron recuperaciones del $92 \%$ en una quinta etapa, para el dispersor plano, con valores de Jg, de 0,5 y $0,8 \mathrm{~cm} / \mathrm{s}$ y de $\mathrm{Jl}$, de $0,19 \mathrm{~cm} / \mathrm{s}(2,7 \mathrm{l} / \mathrm{min})$. Para el dispersor cilíndrico, la recuperación máxima fue de $97 \%$, siendo el valor de Jg de $1,0 \mathrm{~cm} / \mathrm{s}$ y de Jl de $0,31 \mathrm{~cm} / \mathrm{s}$. El incremento del $\mathrm{Jl}$ permite procesar un mayor volumen en tiempos relativamente cortos $\mathrm{La}$ constante cinética aparente de flotación mantiene un comportamiento lineal con los parámetros que caracterizan una dispersión $\left(\mathrm{Jg}, \varepsilon_{\mathrm{g}}\right.$ y $\left.\mathrm{Db}\right)$, hasta un punto donde la inestabilidad del proceso vuelve inoperante el sistema. Los resultados muestran que la remoción de iones de metal base por flotación iónica se ve fuertemente afectada por los factores de: [C], Jg, gg, $\mathrm{Db}, \mathrm{Jl}$, y $\mathrm{Sb}$.

\section{Agradecimientos}

Los autores desean expresar su agradecimiento al gobierno Mexicano por el apoyo otorgado al proyecto FOMIX 97579 CONACyT.

Figura 15. \% w/w recuperación acumulativa cobre Vs. numero de celda de flotación, a diferentes velocidades superficiales de liquido JI, Jg constante 0,8 . a) dispersor plano. b) dispersor cilíndrico.

Figure 15. \% w/w accumulative recovery copper, vs. flotation cell number at several superficial liquid velocities $\mathrm{Jl}(\mathrm{cm} / \mathrm{s}) \mathrm{Jg}$ constant 0.8 , a) flat sparger. b) cylindrical sparger. 


\section{Nomenclatura}

A Área de sección transversal de la celda, $\mathrm{cm}^{2}$

[c] Concentración de colector

$\mathrm{D}_{\mathrm{b}} \quad$ Diámetro de burbuja, $\mathrm{cm}$

DTR Distribución del tiempo de residencia.

[e] Concentración de espumante.

$\mathrm{FM}_{\mathrm{A}} \quad$ Flujo másico de alimentación.

$\mathrm{FM}_{\mathrm{C}}$ Flujo másico del concentrado.

$\mathrm{FM}_{\mathrm{T}} \quad$ Flujo másico de colas.

$\mathrm{J}_{\mathrm{g}} \quad$ Velocidad superficial de gas, $\mathrm{cm} / \mathrm{s}$.

jI Velocidad superficial de líquido, $\mathrm{cm} / \mathrm{s}$.

$\mathrm{Jl}_{\mathrm{A}} \quad$ Velocidad superficial de líquido de alimentación, $\mathrm{cm} / \mathrm{s}$.

$\mathrm{Jl}_{\mathrm{c}}$ Velocidad superficial de líquido de colas, $\mathrm{cm} / \mathrm{s}$.

$Q_{1} \quad$ Flujo volumétrico de líquido 1/min.

$Q_{\mathrm{lc}} \quad$ Flujo volumétrico de colas $1 / \mathrm{min}$.

$Q_{g} \quad$ Flujo volumétrico de gas $1 / \mathrm{min}$.

$\mathrm{S}_{\mathrm{b}} \quad$ Flujo de área superficial de burbujas, $\mathrm{cm} / \mathrm{s} / \mathrm{cm}$

$\mathrm{t}$ Tiempo.

Vzc Volumen de la zona de colección.

$\varepsilon_{\sigma} \quad$ Fracción de gas retenido

$\Delta_{g} P \quad$ Diferencia de lecturas entre manómetros.

$\Delta H \quad$ Alturas entre manómetros, $\mathrm{cm}$.

$\rho \quad$ Densidad del liquido, $\mathrm{g} / \mathrm{cm}^{3}$

$\tau \quad$ Tiempo de residencia aparente

$\gamma \quad$ Tensión superficial, dinas $/ \mathrm{cm}$.

$\kappa \quad$ Constante cinética de flotación $\mathrm{min}^{-1}$ aparente.

\section{REFERENCIAS}

[1] Tratado universal del medio ambiente, Tomos 4 y 8, Ed. Rezza, México, 1993,. pp. 31-37, 489-512.

[2] F. Sebba, Ion flotation, Ed. Elsevier, New York, EE. UU., 1962, pp. 1-30.
[3] The Dow Chemical Company, 1981, pp. 1-16.

[4] J.A. Finch y G.S. Dobby, Column flotation. Pergamon Press, Oxford, Inglaterra, 1990, pp1025.

[5] F.J. Tavera, R. Escudero, U. Salas. y J.A. Finch, Afinidad 490 (2000) 415-423.

[6] F. Doyle, Int. J. Miner. Process 72 (2003) 387399

[7] M.T. Ityokumbol, Miner. Eng. 12 (1993) 1.2791.286.

[8] M. Xu, J.A Finch, Can. Metall. Q. 28 (1989) 16.

[9] F.J. Tavera, R. Escudero, C.O. Gomez y J. A Finch, Int. J. Miner. Process. 61 (2001) 23-40 metall.(1996) 105.

[10] NTE-CCA 031/91. Diario oficial de la federación.

[11] G. S. Dobby, J. B, Yianatos, y J. A. Finch, Can. Metall. Q. 272 (1988) 85-90.

[12] J.B. Yianatos, J.A Finch, G.S. Dobby y X. Manquiu, J. Colloid Interf. Sci. 126 (1988) 3744.

[13] R. Escudero, O. C. Gómez y J. A. Finch, Can. J. Chem. Eng. 78 (2000) 785-792.

[14] W. Zhang, M. Kolahdoozan, J.E. Nesset y J.A. Finch, Miner. Eng. 22 (2009) 513-515.

[15] M. Bailey, C. O. Gomez y J. A. Finch, Miner. Eng. 8 (2005) 119-123.

[16] F. Chen, C. O. Gomez y J. A. Finch, Miner. Eng. 14 (2001) 427-432.

[17] F. J. Tavera, C. O. Gomez y J. A. Finch, Can. Metall. Q. 37 (1998) 19-25.

[18] F. J. Tavera y R. Escudero, Trans. Inst. Min. Metall C (2002) 111.

[19] D. Lelinski, J. Allen, L. Redden y A. Web, Miner. Eng. 15 (2002) 499-505.

[20] www.sc.ehu.es/sbweb/fisica/fluidos/tension/burbuja/burbuja.htm (enero 2009). 